\title{
Preparation of Nanofluid (Al2O3-water) for Energy Storage
}

\author{
Adil Mohammed Hashim ${ }^{1}$,FarhanLafta Rashid ${ }^{2}$ and Ibrahim Kaittan Fayyadh \\ Ministry of Science and Technology, Baghdad-Iraq
}

\begin{abstract}
Nanofluids are suspensions of nanoparticles in base fluids, a new challenge for thermal sciences providedby nanotechnology. Nanofluids have unique features different from conventional solid-liquid mixtures inwhich $\mathrm{mm}$ or $\mu \mathrm{m}$ sized particles of metals and non-metals are dispersed.At this research adding of small weight percent of Aluminum oxide (Al2O3) for weight percent of (0.1, 0.2, 0.3 and $0.4 w t . \%)$ to pure water as energy storage in different industrial applications, which gave us different behavior, adding 0.1, 0.2 and $0.4 w t, \%$ gave low temperature gradient than the pure water, while $0.3 \mathrm{wt} . \%$ gave greater temperature gradient than pure water which is desired.
\end{abstract}

Keywords: Nanomaterials, Nanofluids, Thermal Energy, Energy Storage.

\section{Introduction}

Nanofluids are solid-liquid composite materials consisting of solid nanoparticles or nanofiberswith sizes typically of $1-100 \mathrm{~nm}$ suspended in liquid. It has been shown that nanoparticles with higher thermal conductivity than their surrounding liquid can increase the effective thermal conductivity of suspension. Forexample, a small amount ( $<1 \%$ volume fraction) of $\mathrm{Cu}$ nanoparticles or carbon nanotubes dispersed in water or oil was reported to increase the inherently poor thermal conductivity of the liquid by $74 \%$ and $150 \%[1,2]$.

Nanotechnology provides new area of research to process and produce materials with average crystallite sizes below $100 \mathrm{~nm}$ called nanomaterials. The term "nanomaterials" encompasses a wide range of materials including nanocrystalline materials, nanocomposites, carbon nanotubes and quantum dots[4].

Nanofluids clearly exhibit improved thermo-physical properties such as thermal conductivity, thermal diffusivity, viscosity and convective heat transfer coefficient. The property change of nanofluids depends on the volumetric fraction of nanoparticles, shape and size of the nanomaterials as shown by Yang et al. [5]. Heat transfer fluids have inherently low thermal conductivity that greatly limits theheat exchange efficiency. While the effectiveness of extending surfaces and redesigningheat exchange equipments to increase the heat transfer rate has reached a limit, manyresearch activities have been carried out attempting to improve the thermal transportproperties of the fluids by adding more thermally conductive solids into liquids. Liquid dispersions of nanoparticles, which have been termed "nanofluids", exhibit substantiallyhigher thermal conductivities than those of the corresponding base fluids [6].

Very high thermal conductivity and extreme stabilityhave always been desired for heat transfer fluids withparticles. Fluids having this important combination of featuresdid not exist till the advent of nanofluids. Nanofluid technologycould make the process more energy efficient and costeffective.Thesenanofluids could be used in a wide rangeof industrial applications. Demand for ultra-high-performancecooling in electronics has been increasing, and conventional enhanced surface techniques have reached their limit withregard to improving heat transfer. Since nanoparticles arerelatively much smaller than the diameter of microchannelflow passages, smooth-flowing nanofluids could providethe solution. Since nanofluids can flow in microchannelswithout clogging, they would be suitable coolants. Thesecould enhance cooling of MEMS under extreme heat fluxconditions [7].

Specific heat capacity of solvents can also be enhancedby doping with nanoparticles. Nelson et al. [8]reportedthat the specific heat capacity of polyalphaolefin was enhancedby $50 \%$ on addition of ex-foliated graphite nanoparticles at $0.6 \%$ concentration by weight. Shin and Banerjee [9]synthesized moltensalt-based silica nanofluid and observed $26 \%$ enhanced specificheat capacity for $1 \%$ weight concentration.

Thermal energy storage_TES_ systems at high temperatures arerequired to improve the operational efficiencies and reliability ofsolar thermal energy conversion systems. The materials that arecompatible for these applications _ such as alkali-nitrates, alkalicarbonates, and alkali-chlorides _as well as their eutectics_havevery low specific heat capacities, usually less than $2 \mathrm{~J} / \mathrm{g} \mathrm{K}$ _while, to compare, the specific heat of water is $4.2 \mathrm{~J} / \mathrm{g} \mathrm{K}$ atroom temperature.

The thermal conductivity of these materials isalso low _usually, $1 \mathrm{~W} / \mathrm{m} \mathrm{K}^{0}$. The thermophysical properties ofmolten salts can be improved by doping with small quantities ofnanoparticles, thus realizing a high temperature nanofluid[10]. 
Direct absorption solar collectors have been proposed for a variety of applications such as water heating; however the efficiency of these collectors is limited by the absorption properties of the working fluid. Otanicar et al. [3] demonstrated efficiency improvements of up to $5 \%$ in solar thermal collectors by utilizing nanofluids as the absorption mechanism. The experimental and numerical results demonstrate an initial rapid increase in efficiency with volume fraction, followed by a leveling off in efficiency as volume fraction continues to increase.

In this research we prepared nonofluid (A12O3-Water) of different weight percent for thermal energy storage in many industrial applications.

\section{Results and Discusion}

Results were obtained for adding Alumna (nanoparticles of 20 to 30 nanometer) with 0.1, 0.2, 0.3 and 0.4 wt.\% to pure water .

Figure(1) shows the relationship between the temperature of the heating fluid with heat loss time, one can observe that when adding $(0.1,0.2$ and $0.4 \mathrm{wt} . \%$ of Al2O3) to pure water the temperature gradient will less than the case of pure water because it will minimize the heat capacity of the whole mixture(Al2O3-Water), while when adding $0.3 \mathrm{wt} . \%$ the temperature gradient will be greater than the pure water casewhich is desired.

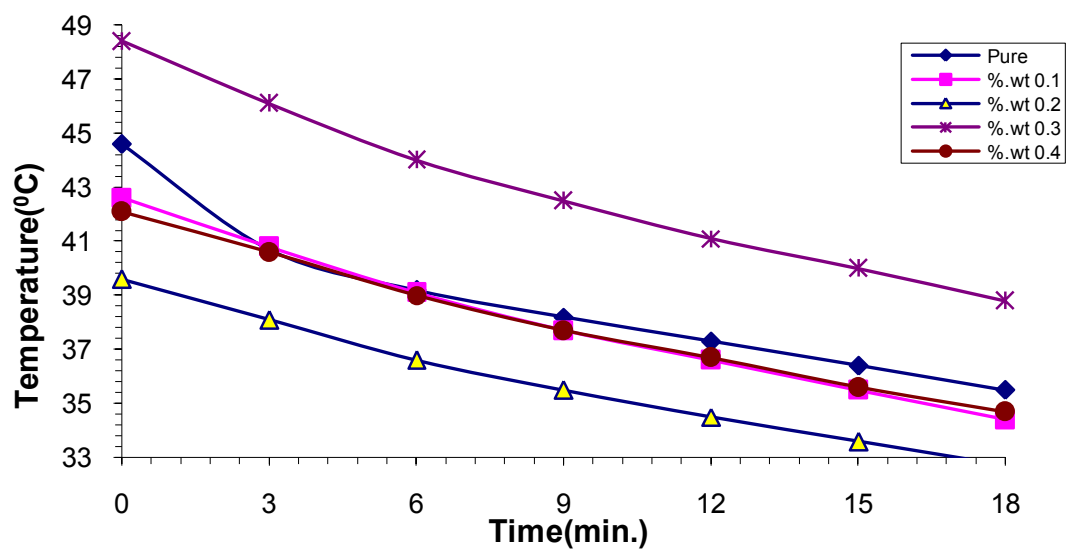

Figure (1) Variation of Storage Temperature with time of Al2O3-Water (Nanofluid)

\section{Conclusions}

From the present work we can deduce the following conclusions:

1. Adding nanoparticles (Al2O3) to pure water at small quantities $(0.3 \%)$ will minimize the heating loss time. also ability to heat gain is greater than pure water.

2. Adding nanoparticles (Al2O3) to pure water for $(0.1,0.2$ and $0.4 \mathrm{wt} . \%)$ will maximize the heating loss time, ability to heat gain is less than the case of pure water.

3. It is possible to save energy by very small quantities of nanoparticles.

\section{References}

[1] S. Jana, A.S. Khojin,W.H. Zhong, Thermochim. Acta 462 (2007) 45-55.

[2] S.U.S. Choi, Z.G. Zhang,W. Yu, et al., Appl. Phys. Lett. 79 (2001) 2252-2254.

[3] T.P.Otanicar, P. E. Phelan, R.S Prasher,G.Rosengarten, \& R. A.Taylor,(2010), Nanofluid -based direct absorption solar collector, Journal of renewable and sustainable energy, 2 .

[4] Gupta H.K, Agrawal G.D, Mathur J.(2012),An overview of Nanofluids: A new media towards green environment, INTERNATIONAL JOURNAL OF ENVIRONMENTAL SCIENCES Volume 3, No 1, 2012.

[5] Yang Y, Zhang Z G, Grulke E A, Anderson W B \& Wu G., (2005),Heat transfer properties of nanoparticle-in-fluid dispersions (nanofluids) in laminar flow, International Journal of Heat and Mass Transfer, 48(6), pp1107-1116.

[6] Zenghu Han,(2008),Nanofluids with Enhanced Thermal TransportProperties, Thesis.

[7] A. K. Singh,(2008), Thermal Conductivity of Nanofluids, Defence Science Journal, Vol. 58, No. 5, September 2008 , pp. 600 -607.

[8] I.C. Nelson, D. Banerjee, R. Ponnappan, Flow loop experiments usingpolyalphaolefin, J. Thermophys. Heat Transfer 23 (2009) $752-761$.

[9] D. Shin, D. Banerjee, Enhanced specific heat of silica nanofluid, ASME J. HeatTransfer 133 (2011) 024501-024504, doi:10.1115/1.4002600.

[10] Donghyun Shin (2011), Enhanced Specific Heat of Silica Nanofluid, Journal of Heat Transfe ,FEBRUARY 2011, Vol. 133 / $024501-1$. 